\title{
A avaliação como instrumento eficaz para a qualidade do processo de alfabetização de jovens e adultos
}

No processo de alfabetização de adultos a avaliação é uma das ferramentas imprescindíveis, visto que os alunos precisam constantemente saber como está a sua aprendizagem. Contudo, o professor também necessita estar sempre sendo perceptível ao seu próprio planejamento, por meio do resultado das suas ações, as quais podem possibilitar uma transformação no ato de ensinar e aprender. A avaliação é mediação entre o ensino do professor e a aprendizagem do aluno. É o 'fio' da comunicação entre formas de ensinar e formas de aprender. Para isso, é preciso considerar que os alunos aprendem diferentemente porque tem histórias de vidas diferentes, ou seja, são sujeitos históricos e isso condiciona sua relação com o mundo, e influencia sua forma de aprender. Os estudos teóricos que trazem orientações sobre aprendizagem na alfabetização de jovens e adultos são realizados com a finalidade de contribuir para a melhoria na qualidade de ensino e, no caso da alfabetização de jovens e adultos especificamente, buscam-se entender as dificuldades nesse processo de ensino para ver da possibilidade de outras formas de avaliação além daquelas que costumeiramente são usadas.

Palavras-chave: Avaliação; Qualidade de Ensino; Jovens e Adultos.

\section{Evaluation as an effective instrument for the quality of the youth and adult literacy process}

In the adult literacy process, assessment is one of the essential tools, as students constantly need to know how their learning is. However, the teacher also need to be always aware of his own planning, through the result of his actions, which can enable a transformation in the act of teaching and learning. Assessment is a mediation between teacher teaching and student learning. It is the 'thread' of communication between ways of teaching and ways of learning. Therefore, it is necessary to consider that students learn differently because they have different life histories, that is, they are historical subjects and this conditions their relationship with the world, and influences their way of learning. The theoretical studies that provide guidance on learning in youth and adult literacy are carried out in order to contribute to the improvement of teaching quality and, in the case of youth and adult literacy specifically, seek to understand the difficulties in this teaching process. to see the possibility of other forms of assessment than those commonly used.

Keywords: Assessment; Quality of Education; Youth and Adults.

Topic: Avaliação da Aprendizagem

Reviewed anonymously in the process of blind peer
Received: $14 / 10 / 2019$

Approved: 02/02/2020
Ismael Antonello Pereira (iD

Universidad de Desarrollo Sustentable, Paraguai

http://lattes.cnpq.br/6418719578967291

http://orcid.org/0000-0002-4846-888X

ismael.warrior@hotmail.com
Referencing this:

PEREIRA, I. A.. A avaliação como instrumento eficaz para a qualidade do processo de alfabetização de jovens e adultos. Educationis, v.8, n.1, p.37-52, 2020. DOI: http://doi.org/10.6008/CBPC2318-

\section{$\underline{3047.2020 .001 .0004}$}




\section{INTRODUÇÃO}

No processo de educação de adultos a avaliação é uma das questões de muita importância pelo fato de que os alunos precisam constantemente saber como está a sua aprendizagem e o professor necessita estar sempre revendo situações referentes ao processo de ensino. A avaliação é mediação entre o ensino do professor e a aprendizagem do aluno. É o 'fio' da comunicação entre formas de ensinar e formas de aprender. Para isso, é preciso considerar que os alunos aprendem diferentemente porque têm histórias de vidas diferentes, pois são sujeitos históricos e isso condiciona sua relação com o mundo influenciando sua forma de aprender. Por isso, os estudos teóricos que trazem orientações sobre aprendizagem na alfabetização de jovens e adultos são realizados com a finalidade de contribuir para a melhoria na qualidade de ensino e, no caso da educação de jovens e adultos especificamente, buscam-se entender as dificuldades nesse processo de ensino para ver a possibilidade de outras formas de avaliação além daquelas que costumeiramente são usadas.

É sabido que avaliar não é apenas constatar, mas, sobretudo, analisar, interpretar, tomar decisões e reorganizar o ensino, esta perspectiva está presente na obra de Hoffmann (1996) que propõe a avaliação mediadora numa visão libertadora. Exige-se ação reflexão, a qual reorganiza o saber através de diálogo do professor e do aluno. Já Luckesi (1996), defende a avaliação diagnóstica como instrumento dialético, assim tornando o ensino dinâmico e democrático. Perrenoud (1996), apresenta a avaliação formativa enquanto um complemento pedagógico de uma pedagogia diferenciada, centrada no desenvolvimento de competências.

A Educação de Jovens e Adultos, como modalidade da Educação Básica nos níveis fundamental e médio, atende atualmente o público de diversas idades e não escolarizado ou que não pôde continuar a sua escolarização por fatores diversos, na maioria das vezes, alheios à sua vontade. As propostas pedagógicas e também curriculares relacionadas ao EJA, têm a possibilidade de, mesmo que de forma parcial oferecer muita oportunidade de educação e inclusão dessas pessoas. Para tal muitos critérios são necessários entre eles: a flexibilização de horários e outras adaptações à realidade desses alunos. Assim, necessariamente a avaliação também se faz necessária com critérios diferenciados e repensados para esse fim. Segundo Luckesi (1978) “ a avaliação é um julgamento de valor sobre manifestações relevantes da realidade tendo em vista uma tomada de decisões". Habitualmente quando se "[...] fala em Avaliação, se pensa, de forma própria ou mesma exclusiva, nos resultados obtidos pelos alunos". Contudo, a "avaliação faz parte do processo educativo, e como tal merece toda atenção e compromisso do professor" (HOFFMANN, 1995).

Os diferentes tipos de avaliações podem e devem ocorrer durante o processo de aprendizagem tentando se adequar a que se enquadra melhor em cada momento. É possível que possa se iniciar com uma avaliação diagnóstica ${ }^{1}$ no início do processo de avaliação, uma avaliação durante o processo, a avaliação formativa ${ }^{2}$ e depois uma avaliação somativa ${ }^{3}$ que, segundo Rabelo (1998) é aquela que acontece no final do

\footnotetext{
${ }^{1}$ A avaliação diagnóstica busca conhecer, principalmente as aptidões, os interesses e as capacidades e competências enquanto pré-requisitos para futuros trabalhos (RABELO, 1998).

${ }^{2}$ A avaliação formativa ocorre no decorrer do processo e busca informações sobre estratégias de solução dos problemas e das dificuldades surgidas (RABELO, 1998).

3 É o processo avaliativo que ocorre no final do processo e busca observar comportamentos globais, socialmente adquiridos e, se possível, dar certificações (RABELO, 1998).
} 
processo ou no final de um ciclo seja bimestral, no final de uma unidade de ensino ou no final do curso. No caso do processo de ensino-aprendizagem e educação de adultos a avaliação formativa, somada a avaliação diagnóstica inicial e a avaliação somativa, essa sem necessidade de critérios de pontuação, valores numéricos ou percentuais, juntas vão permitir que o aluno possa mudar de nível ou esteja apto a concluir uma etapa de aprendizagem.

\section{METODOLOGIA}

Para o desenvolvimento desse artigo foram utilizados os procedimentos de pesquisa bibliográfica, buscando discutir a avaliação de forma qualitativa dentro da educação de jovens e adultos. Foi discutido sob o ponto de vista que a avaliação se faz necessária a todo o processo educacional, mas que no sistema de educação de jovens e adultos, principalmente aqueles vinculados ao projeto de trabalho de alfabetização, percebeu-se a necessidade de estudo e abordagem de diversos autores. Dentre os autores lidos e escolhidos para análise procurou-se enfatizar aqueles que abordavam sobre avaliação mais especificamente. Para buscar contemplar as diferentes formas de avaliar e os diferentes conceitos de avaliação procurou-se centrar o estudo em autores como Hoffmann, Perrenoud, Luckesi, Rabelo e outros que demonstram uma abordagem que foi considerada adequada ao nível educacional pretendido, ou seja, a educação de jovens e adultos.

\section{DISCUSSÃO TEÓRICA}

\section{Concepções de Avaliação}

A partir da crítica ao modelo tradicional avaliativo, centrado na pessoa do professor voltado para o domínio da prática e dos conteúdos conforme apresenta (LUCKESI, 1996) e se aproximando da realidade educacional é muito comum emergirem questões como salário dos professores, número de alunos por sala, carga horária, aula semanais da disciplina, falta de equipamentos, formação profissional, condições para aquisição de livros, tempo para estudo, desinteresse dos alunos, o não apoio da família, desvalorização do profissional da educação, material didático, burocracia, rotatividade dos professores, indisciplina, autoritarismo dos dirigentes, teoria desarticulada da prática, falta de plano de carreira ou outras questões. Tais questões tentam justificar o uso de uma avaliação tradicional por ser ela mais cômoda mais tranquila e mais eficiente sobre o ponto de vista de alguns professores.

Identificadas as concepções sobre o ato avaliativo, dentre elas a avaliação mediadora Hoffmann, (1996), avaliação diagnóstica Luckesi (1996) e Gandin (1998) e avaliação formativa Perrenoud (1999) as quais permite ao professor analisar, interpretar, formar decisões e reorganizar o ensino. Nesse sentido, a avaliação tradicional passa a ter um caráter no qual possa ser responsabilizado o aluno pelo seu sucesso ou seu fracasso; que além de ser e de consequentemente levar a exclusão, não permite descobrir as falhas do próprio processo escolar e de ensino-aprendizagem, por focar apenas o aluno, impedindo uma renovação da prática pedagógica.

Necessária a todo o tipo de aprendizagem e a qualquer nível de ensino a avaliação se torna cada vez 
mais um processo complexo. A complexidade não está no processo de avaliar, mas sim em qual concepção de avaliação deve ser adequada determinadas situações. Toda prática educativa precede um processo avaliativo. A avaliação, como verificação do ensino-aprendizagem está cotidianamente acontecendo e já se tornou uma exigência tanto para o professor quanto para o aluno. De acordo com Hoffmann (1995) "avaliação faz parte do processo educativo, e como tal merece toda atenção e compromisso do professor". Somente o ato de avaliar é capaz de garantir o conhecimento dos resultados, dos objetivos previstos e alcançados, da organização dos conteúdos e das práticas que possam ser mais eficientes ou que estejam mais próximas da realidade do aluno ou do contexto ao qual ele está inserido.

Há, para diversos autores na literatura diversos formas de definirem e conceituarem avaliação. Seja ela entendida como aferição, verificação, medida, sondagem ou ponto de partida, ela necessariamente precisa garantir uma intervenção no processo de ensino e aprendizagem para que se garantam resultados não só em relação ao trabalho do professor, mas também do aprendizado do aluno e, no que se refere ao trabalho com jovens e adultos, estes querem ver já logo após todas as atividades o resultado do seu empenho ou a sua possibilidade de superação de dificuldades no processo de aprendizagem. Segundo Berger (2011) “A avaliação é uma ação presente em nosso dia a dia, pois sempre estamos diante de situações que exigem análise e tomada de decisão".

Entende-se por processo o que correspondem a todos os segmentos e contextos envolvidos no ensino-aprendizagem incluso professores, gestores, alunos e escola como um todo para que ela seja facilitadora ou promotora do conhecimento. Nesse sentido avaliar é um processo que consiste em buscar realizar sempre um acompanhamento contínuo do currículo e estratégia, dos procedimentos. Através de registros e análises que busquem detectar dificuldades procurando através da interpretação de dados e resultados delinear os planos e objetivos.

Nesse sentido, aprender é o ato de trazer uma modificação passageira ou duradoura, no comportamento do indivíduo. A avaliação por sua vez buscará além de simples aplicação de provas verificar o rendimento e o real aprendizado do aluno e também o resultado do trabalho do professor. Desse modo, aprender está relacionado com verificar, não no sentido apenas de checar, olhar, mas no sentido de conferir, analisar, saber quais foram os avanços e em que ainda precisa ser melhorado ou mudado. No caso da alfabetização de adultos se faz necessário contextualizar a sua aprendizagem com a sua vida pessoal.

Assim, segundo Luckesi (1996) quando a avaliação assume o caráter de verificar (no seu sentido etimológico - do latim - verum facere $=$ fazer verdadeiro) e de observação, análise dos dados e informação ela passa a ter o sentido de (a-valere), ou seja, a dar ou atribuir valor a algo dando qualidade seja a objetos, ação ou a processo como no caso do processo educacional. Assim, "O processo de verificar configura-se pela observação, obtenção, análise e síntese dos dados e informações que delimitam o objeto ou o ato com o qual está trabalhando" (LUCKESI, 1996).

Nesse sentido, a diferença entre avaliar e medir é que medir diz quanto o aluno possui de certa habilidade e avaliar informa sobre o valor dessa habilidade. Há, no entanto alguns equívocos quando se define avaliar com o mesmo sentido de testar e medir. Já segundo Hoffmann (2000) “a medida assume 
muitas vezes papel absoluto nas decisões de eliminação e enquanto teste é entendido como instrumento de constatação e mensuração e não de investigação". O equívoco é quando se atribuem valores numéricos a questões relacionadas à vida pessoal ou a atitudes que alunos manifestam na escola ou ainda a algumas produções textuais ou a desenhos.

No caso da alfabetização de adultos a avaliação deve estar fundamentada na teoria de que a aprendizagem se dá na tentativa, no ensaio e no erro. Assim, ainda segundo Hoffmann (2000) é importante que na "[...] dimensão educativa os erros e dúvidas sejam considerados como episódios altamente significativos e impulsionadores da ação educativa, permitindo que a avaliação seja dinâmica na criação de oportunidade de ação-reflexão", permitindo que as hipóteses formuladas pelo aluno sejam base para a formulação do conhecimento científico. Porém isso só será possível quando a avaliação deixar de ser realizada em um momento final e acontecer de forma que se busque incessantemente a compreensão das dificuldades do educando e na possibilidade de oportunidades e de novas chances de que se chegue ao conhecimento. A avaliação não deve ser encarada com uma possibilidade de se dar o parecer final de um fracasso ou de um sucesso e sim ser encarado como uma oportunidade ensino, para que, encontradas as dificuldades sejam possíveis novas atitudes, seja revista à metodologia e tudo o que possa garantir a aprendizagem.

\section{A avaliação e a Aquisição de Conhecimento}

Saviani (1985) defende a teoria de que a conversão do saber em saber escolar objetivo, sendo que este deve ser colocado de modo que garanta a assimilação pelos educandos tanto no espaço quanto no tempo escolar, contando sempre com materiais e meios que não garantam apenas a aquisição do saber objetivo, mas principalmente aprendam o no processo em que ele se produz. No que se refere a tempo escolar e espaço é necessário, na alfabetização e educação de adultos, levar em consideração cada aluno em particular por este estar, em algumas vezes, devido a sua idade ou ao tempo que parou de estudar ou que estudou, 'fora' do seu tempo de aprender, ou seja, já estar fora da possibilidade de inclusão no ensino regular, muitas vezes pode ficar constrangido ou com vergonha de assumir que não sabe ler ou expressar-se por escrito por ter conhecimento e entendimento sobre muitas outras coisas que ele já tenha aprendido em tempo hábil, tais como trabalhar, ter conceitos próprios em relação a sua vida pessoal e vivência em sociedade ou no modo de sobrevivência e outros aprendizados que foram sendo desenvolvidos desde a infância.

Para Libâneo (1999), "a avaliação é uma tarefa didática necessária permanente do trabalho docente e que deve acompanhá-lo sempre em todo o processo de ensino-aprendizagem". É através dela que é possível verificar os resultados e analisar os objetivos propostos tanto para o professor tanto para o aluno. A avaliação é sempre uma reflexão sobre a qualidade e a garantia dela em todo o trabalho escolar. Hoffmann (1991) afirma que a avaliação tem que ser constante pois a docência não é uma verdade absoluta e precisa ser analisada de caráter investigativo. E segundo a autora não se trata de simplesmente transmitir e corrigir é preciso uma eficiente construção do conhecimento. 
Vasconcelos (1986) considera a avaliação escolar como uma questão política, no sentido de estar relacionada ao poder, aos objetivos, às finalidades. "A avaliação enquanto processo precisa ser contínuo, no momento certo e que garanta a verificação da construção de conhecimentos". Para o mesmo autor ainda a avaliação tem papel de inculcação ideológica e seleção social por representar controle, julgamento e serve algumas vezes para a ascensão social. Libâneo (1999) afirma ainda ser: a avaliação um componente do processo de ensino que visa com a verificação dos resultados conseguidos, buscar novos objetivos e verificar o já alcançado orientando novas decisões.

Já para Luckesi (1986), "a avaliação é um julgamento de valor sobre a manifestação mais relevante para tomadas de decisão". Ela é uma apreciação qualitativa sobre os dados que são relevantes, dados esses que se referem as mais diversas manifestações nas quais professores e alunos sem empenham em busca de uma única finalidade, o ensino-aprendizagem. A avaliação serve como auxílio ao professor na sua tarefa de ensinar e dos próprios alunos verificar sua aprendizagem que por sua vez, segundo Hoffmann (1991) "quando dá algumas vezes uma ideia de provas, testes que consequentemente provocam nervosismo, opressão, medo". Para Hoffmann (1995), a avaliação mediadora significa o desenvolvimento máximo possível, sem limites pré-estabelecidos, embora com objetivos claramente delineados, desencadeados da ação educativa, ou seja, saber onde se quer chegar.

Assim, para a construção eficiente do conhecimento do aluno é necessário que se efetive, entre professor, escola e aluno, propostas muito claras sobre o que, como e quando avaliar. A avaliação considerada de uma perspectiva democrática, só poderá ocorrer quando for superado o caráter de terminalidade e de mediação de conteúdos aprendidos, para que os resultados da avaliação possam ser concebidos como indicadores para a reorientação da prática educacional e não como forma de estigmatizar o aluno. Segundo Araújo (2007) o processo de avaliação precisa ser visto com um instrumento pedagógico, não como uma forma de punição.

No contexto da alfabetização de adultos que muitas vezes tem dificuldades de realizar tarefas simples e corriqueiras para o alfabetizado, dessa forma o erro não pode ser levado em consideração a ponto de desmotivá-los ou de fazê-los desistir de tentar. Entende-se que a condenação do erro é o que leva alunos a se evadirem da escola ou a não insistirem em superar dificuldades. Esses, quando desistem e voltam posteriormente já vem com certo receio ou com uma rotulação algumas vezes é o que dificulta ainda mais as suas tentativas de aprendizagem.

No que trata da educação de jovens e adultos é preciso bastante empenho tanto do aluno quanto do professor para superar algumas questões referentes ao erro que muitas vezes têm um aspecto negativo ou que determina ao aluno o seu fracasso ou a sua dificuldade em relação à construção do conhecimento. Na concepção da avaliação tradicional está embutido o conceito de uma prática educativa repressora, que reprova, rotula, estigmatiza. Essa prática impede o processo de conhecimento por achar que a educação tem nela um fim ou um único objetivo. Nesse caso, no processo de educação e alfabetização de adultos, uma das soluções e sugestões para a correção de todas as atividades é que elas deviam ocorrer na sala de aula, tendo assim a oportunidade de chamar o aluno para discutir as correções para que juntos, professor e aluno, 
possam buscar a melhor forma para aquele contexto de aprendizagem. Contudo, Freire (1983), destaca que “é a partir dessa interação entre professor e aluno, desta troca de informações e do reconhecimento de aspectos relevantes à aprendizagem ocorrerá de fato".

Apenas chegar à conclusão de que algo está certo ou errado não leva a nada é preciso que, a partir do diálogo, professor e aluno, tenham um entendimento. É preciso saber qual é o erro e por que está errado. E mais uma vez se justifica a necessidade de a avaliação ser um processo contínuo na construção do conhecimento do aluno e ser uma prática consciente que acompanha outras práticas do professor.

\section{Tipos de Avaliação}

Há muitas formas de avaliar, porém é preciso que o professor tome alguns cuidados para não se equivocar e mudar apenas os instrumentos de avaliação sem mudar a avaliação em si. É possível observar que, na maioria das vezes, por mais que se tente diversificar alguns itens relacionados ao ato de avaliar o que ainda ocorre é a avaliação tradicional. Hadji (2001) confirma que por muito tempo se pensou em apenas "atribuir um número a um conhecimento ou a um objeto de acordo com uma regra logicamente aceitável, implicando que o objeto ou acontecimento pode ser apreendido sob uma única dimensão, isolável, capaz de receber uma escala numérica".

Nessa perspectiva a pedagogia centraliza a atenção na avaliação com provas e exames e não busca auxiliar a aprendizagem do aluno, e num processo em que o professor está esquecendo o sentido da prática educativa e pode até conceber os conceitos de avaliação, ou mesmo que ela aconteça num processo contínuo, se não mudarem os critérios ela continuará a ter uma visão de avaliação classificatória e excludente. A avaliação de aprendizagem serve para garantir a qualidade do ensino-aprendizagem do aluno e do professor. Ela tem a função de possibilitar uma qualificação da aprendizagem. Observar bem que estamos falando de qualificação do aluno e não de classificação.

A avaliação dever ter como função um caráter de libertadora ${ }^{4}$, a qual é capaz de ajudar a escola a cumprir sua função social transformadora que favoreça os alunos e leve-os a aprender melhor, comprometendo-se com uma sociedade melhor. Segundo Hoffmann (2000) "O sentido fundamental da ação avaliativa é o movimento, a transformação". Assim, a avaliação está relacionada ao ato de recuperação de aprendizagem e de superação de dificuldades em todo o processo, principalmente quando se trata de alfabetização. Dessa forma, falar em recuperação consiste em procurar vê-la como uma saída para que se busque a retomada de conteúdos e conceitos para que ocorra o efetivo conhecimento e não somente a aplicação de uma nova prova ou de um trabalho valendo nota com o objetivo apenas de recuperar número sem preocupar-se em recuperar ou permitir a efetiva aprendizagem. A recuperação deve ser realizada após ser diagnosticada não somente as notas baixas, mas sim o desenvolvimento da aprendizagem.

\footnotetext{
${ }^{4}$ Segundo Hoffmann (2000) a avaliação numa visão libertadora tem ação coletiva e consensual. É investigativa, reflexiva. Tem como proposição de conscientização das desigualdades sociais e culturais. Ela tem postura cooperativa entre os elementos da ação educativa. Privilegia a compreensão. Oferece uma consciência crítica e responsável, sobre o cotidiano.
} 


\section{Avaliação Mediadora}

Ultimamente tem-se discutido muito sobre a avaliação no processo educativo buscando superar a concepção de um instrumento ameaçador e autoritário onde continua sendo um dos grandes temas da educação contemporânea. A avaliação não deve excluir classificar ou rotular o educando, ela, necessariamente precisa servir de meio para que se chegue efetivamente ao conhecimento. Ela deve mediar o ensino e a aprendizagem. Assim, segundo Hoffmann: O caminho para o desenvolvimento é uma "educação igualitária, que acolha os filhos dessa geração em conflito e projete essa geração no futuro, conscientes do seu papel numa possível transformação" (2000).

Assim, para a autora não há certo nem errado, quando falamos em avaliação, porém desafios principalmente à influência de estórias de vida e do aluno e do professor é que norteiam o modo de acontecer o trabalho avaliativo na sala de aula. É necessário considerar que a avaliação deve fazer e faz parte do processo educacional e está a ele relacionada, porém o que há necessidade de se considerar são os critérios para a realização dela conforme Hoffmann (1996): A avaliação é essencial para a educação. "Inerente e indissociável enquanto concebida como problematização, questionamento, reflexão sobre a ação". Considerações a respeito da avaliação como um ato de punição para os alunos põe em discussão a reprovação, o trabalho dos educadores e políticas públicas com o objetivo de verem se a reprovação tem se constatado como um prejuízo social-econômico. Em algumas situações alguns modelos e critérios adotados são ineficientes para minimizar essa situação, esquecendo-se que a questão está no processo de avaliação.

A avaliação, quando serve para a mediação no processo entre uma ação e outra, entre uma prática e outra ou na relação que visa o entendimento entre professores e alunos exige algumas mudanças metodológicas as quais exigem também que os educadores tenham que repensar sua prática pedagógica. Ações como avaliar, planejar, recuperar e outros métodos avaliativos precisam ser levado em conta para que, através do diálogo entre professor e aluno, a mediação e a mudança aconteçam.

Os educadores devem ser preparados para realizarem um diagnóstico e não excluir ou punir o aluno. Necessita-se então, de tarefas ou instrumentos avaliativos relevantes, sabendo acompanhar e identificar as dificuldades dos alunos. O professor deve se auto avaliar e seguir um processo de avaliação que seja contínuo. Diante dessa perspectiva, o principal desafio na prática avaliativa escolar talvez seja a dúvida de como lidar com os alunos e suas diferenças. O que se pode considerar neles para saber o que e como avaliar conhecendo a realidade de cada aluno e ou da escola que se trabalha. Muitos dos métodos tradicionais existem e muitas vezes se tornam um obstáculo para a mudança ou abertura de novos caminhos para a avaliação.

Nesse sentido avaliar é um desafio para o professor e para o aluno, pois, são necessários alguns critérios que aumentem as possibilidades de aprendizagens e a forma de ensino conforme cita Hoffmann (1996) que "esse é um desafio que tem de se enfrentar. O maior dentre os desafios é ampliar o universo de educadores preocupados com o fenômeno avaliação, entender-se a discussão do interior das escolas a toda a sociedade". 
Com isso, o tema avaliação torna-se ainda mais problemático em função da contradição entre discurso e prática de educadores, ou pelo medo de agir de forma justa ou injusta em atribuir resultados sobre o desempenho dos alunos. Avaliação não significa uma presença só no ensino, ou passar com formas de técnicas, ela pode se constituir num processo intelectual na prática, pois, refletir também é avaliar, avaliar certo é planejar, replanejar é ver ou orientar os objetivos de sua ação.

Quanto à avaliação classificatória as escolas se justificam que as famílias buscam as escolas mais conservadoras, e em função disso os professores demoram mudar os métodos avaliativos, ficando a pergunta: será que somente através das notas das provas o professor poderá saber se o aluno aprendeu os conteúdos? Segundo (HOFMANN, 1996), "os educadores em geral discutem muito como fazer a avaliação e sugerem métodos diversos, antes, entretanto, de compreender verdadeiramente o sentido da avaliação na escola". Apresentaram-se nos últimos anos alguns programas do governo em alguns estados, como o programa Santa Catarina Alfabetizada, para justificar a evasão e a repetência escolar, assim quando se refere à mudança e possibilidades de eliminar a avaliação os professores se entusiasmam, então, é a atribuição de notas e realização de provas que impede a mudança.

O que se vê através das notas e provas é que o professor fica seguro em relação à cobrança da escola e da família. Nesse sentido, para Hoffmann (1996) "as notas e as provas funcionam como rede de segurança em termos do controle exercido pelos professores sobre seus alunos, da escola e do país sobre os professores, do sistema sobre suas escolas" que, no entanto, "controle esse que não aprece garantir o ensino de qualidade que viemos pretendendo, pois, as estatísticas são cruéis em relação à realidade das nossas escolas" (HOFFMANN, 1996). Diante disso, a escola se torna responsável quando se trata de qualidade de ensino, mas quando se trata de avaliação classificatória, refere-se a critérios de promoções, padrões de comportamento, qualidade é trocada por quantidade pelo sistema de médias.

Tratando-se de atividades da escola que através da avaliação resultam no conhecimento da situação do aluno e do trabalho do professor a avaliação mediadora permite uma melhor aproximação entre a prática do ensino e do processo de aprendizagem. Na avaliação mediadora é necessário compreender os Jovens e Adultos, conhecê-los e procurar entender os seus argumentos, ouvir suas perguntas propondo questões que os desafie para que aconteça a busca de alternativas a uma ação educativa voltada para a autonomia intelectual. É necessário gerar um conhecimento que o professor possa acompanhar, a partir dos dados precisos de seus alunos, como, objetivos, ideias e experiências. Com isso há necessidade de professor e aluno através do diálogo expor suas maneiras de compreender o mundo, mas, é aí que o professor resiste, mais acostumado há décadas com notas bimestrais e semestrais, impossibilitando o diálogo, pois, mesmo com o diálogo é difícil, fica pior se o educador não dialogar.

Contudo, Hoffmann (1996), apresenta ainda: “a ação mediadora se desenvolve em benefício ao educando e dá se fundamentalmente proximidade entre quem educa e quem é educado". A avaliação além de mediação do processo de aprendizagem e do ensino serve também para fazer a mediação entre o professor e o aluno, permitindo um diálogo, uma aproximação. A relação professor e aluno devem ser de forma que além de interação haja bom entendimento dos objetivos do professor enquanto trabalhador e do 
aluno enquanto aprendiz em qualquer situação e principalmente no caso da alfabetização de adultos. Avaliação Mediadora, enquanto uma intervenção entre educadores e educandos possibilita uma boa relação entre ambos especificamente no fato de que o aluno precisa ser reconhecido pelo professor em relação as suas aptidões, possibilidades e limitações. A avaliação deve ser um processo dinâmico, cujo foco deve ser a efetiva aprendizagem do educando e seu desenvolvimento.

\section{Avaliação Diagnóstica ${ }^{5}$}

O sistema de ensino, profissionais da educação, tem suas atenções centradas a formas de avaliação, sabendo que a sociedade, o professor, os pais estão acostumados com a ideia de que desde a educação infantil ao vestibular o aluno depende de fazer provas e é isso que vai fazê-lo bom ou não, enfim acaba se tornando uma ação pedagógica do exame voltada para um treinamento de resolver provas, ficando sempre na expectativa de receber notas. "Avaliação é um processo contínuo e visa um diagnóstico" (VASCONSELLOS, 1996).

No mínimo os educadores precisam respeitar as condições culturais do jovem e do adulto analfabeto. Eles precisam fazer o diagnóstico histórico-econômico do grupo ou comunidade onde irão trabalhar e estabelecer um canal de comunicação entre o saber técnico (erudito) e o saber popular (GADOTTI, 2001). Também, segundo Gandin (1998) "a avaliação deve ser uma ação que não interfira na aprovação do aluno, fazendo sempre uma avaliação diagnóstica, pois a pessoa humana é sempre capaz de crescer". Para Rabelo (1998) a avaliação diagnóstica, melhor sugerida no início do processo tem como objetivos orientar, explorar, identificar, adaptar e predizer. Tal avaliação busca conhecer as aptidões, interesses e capacidades e competência enquanto pré-requisitos para futuros trabalhos. A avaliação formativa, melhor sugerida durante o processo de produção e do ensino-aprendizagem tem como objetivo regular, situar, compreender, apoiar, reforçar, corrigir, facilitar e dialogar. Essa avaliação busca a busca de informações sobre estratégias de solução de problemas e das dificuldades surgidas. E, finalmente, segundo o mesmo autor, a avaliação somativa, com eficiência para depois do processo, com objetivo de verificar, classificar, situar, informar e certificar o aluno no processo final visa à observação de comportamentos numa ação mais global, determinando e certificando os conhecimentos adquiridos. Entende-se essa avaliação como somativa ${ }^{6}$ depois de ter passado pelas demais e não como uma forma de transformar a avaliação em um dado numérico.

A prática escolar predominante hoje se realiza dentro de um modelo teórico de compreensão que pressupõe a educação como um mecanismo de conservação e reprodução da sociedade (LUCKESI, 1996). Como a prática da avaliação escolar está a serviço de um entendimento conservador da sociedade e da

\footnotetext{
${ }^{5}$ A avaliação diagnóstica é aquela que é feita no início do processo de alfabetização, com a intenção de constatar o nível de domínio da linguagem, lacunas de aprendizagem. Tem por finalidade realizar uma sondagem de conhecimentos e experiências já disponíveis no aluno, bem como a existência de pré-requisitos necessários à aquisição de um novo saber. Permite ainda identificar progressos e dificuldades de alunos e professores diante do objetivo proposto conforme Luckesi (1995).

${ }^{6}$ A avaliação somativa oferece subsídios para o registro das informações relativas ao desempenho do aluno. Ela propicia uma 'medida' a ser transformada em nota, número ou conceito a respeito do desenvolvimento do aluno. Para tal são usados diversos instrumentos de avaliação como provas, testes, trabalhos e pesquisas. A sua finalidade é recolher informações que demonstrem resultados sobre o desenvolvimento do aluno possibilitando novas tomadas de decisão de acordo com Perrenoud (1999).
} 
educação parece que se busca um limite para que a avaliação não se submeta aos comandos teóricos ultrapassados. E, em consequência, que os alunos não façam parte de uma educação que não visa priorizar o seu crescimento. Tem-se necessidade de situá-la no contexto pedagógico, ou seja, temos que colocar a avaliação escolar a serviço de uma pedagogia que entenda e esteja preocupada com a educação como mecanismo de transformação social.

A atual prática da avaliação escolar estipulou como função do ato de avaliar a classificação e não o diagnóstico, como deveria ser constitutivamente. Ou seja, o julgamento de valor, que teria a função de possibilitar uma nova tomada de decisão sobre o objeto avaliado, passa a ter função estática de classificar um objeto ou um ser humano histórico num padrão definitivamente determinado. Do ponto de vista da aprendizagem escolar, poderá ser definitivamente classificado como inferior médio ou superior. Classificações essas que são registradas e podem ser transformadas em números e, por isso, adquirem a possibilidade de serem somadas e divididas em médias. Será que o inferior não pode atingir o nível médio ou superior?.

Todos os educadores sabem que isso é possível, até mesmo defendem a ideia do crescimento. Todavia, parece que todos preferem que isto não ocorra, uma vez que optam por, definitivamente, deixar os alunos com as notas obtidas, como forma de 'castigo' pelo seu desempenho possivelmente inadequado. Para (LUCKESI, 1996): “com a função diagnóstica, a avaliação constitui-se num momento dialético do processo de avançar no desenvolvimento da ação, do crescimento para a autonomia, do crescimento para a competência”. A avaliação deve ser entendida como parte do processo de ensino e aprendizagem, pois ela serve para indicar ao professor o momento da aprendizagem dos alunos: os que já compreenderam quais seus avanços, quais suas dificuldades. Só assim é possível ter a possibilidade de intervenção no sentido da superação de tais dificuldades.

Além de permitir que o aluno se torne consciente de seu processo de aprendizagem e perceba seus avanços e suas dificuldades e possa, em conjunto com seu professor, buscar modos de resolver estas dificuldades. A avaliação diagnóstica indica ao professor a necessidade de rever seu planejamento e fazer ajustes na sua prática educacional. Neste sentido, "a avaliação ela é contínua, exigindo uma observação sistemática dos alunos não apenas com relação ao domínio de conceitos de conteúdo específicos, mas também com relação ao desenvolvimento de competências e habilidades".

Verificadas quais as causas que impedem que ocorra a aprendizagem quando se faz da avaliação não só um critério para conhecimento do processo final da aprendizagem, mas quando se buscar conhecer através dela as possibilidades de intervenção e de mudança. Consiste na localização adequada do educando no início do processo de ensino-aprendizagem ou na busca de descoberta de variáveis que estejam causando dificuldades ou facilitando no decorrer do processo. Hoffmann (1993) diz que, "o significado essencial da avaliação é o "prestar muita atenção" no aluno, procurando conhecê-lo para atender suas falas e seus argumentos". Ela é realizada antes do início do processo ensino-aprendizagem e tem como objetivo servir como ponto de partida para uma prática pedagógica mais adequada e eficiente. Pelo fato dela anteceder todo o processo ela pode determinar os pré-requisitos para que se alcance o objetivo; determinar a existência 
de certos domínios e de formas já aprendidas pelo educando, permitindo que se busque um nível mais elevado; permite ainda que se classifiquem interesses e aptidões dos alunos e que se verifique acertos e erros podendo descobrir o que é eficiente ou deficiente, pois; ela tenta identificar o perfil dos sujeitos vê também se é a prática pedagógica, o processo ensino-aprendizagem, o comportamento do educando, o material didático utilizado ou a dinâmica de ensino utilizada pelo professor. Para White (1976) "não basta ao mestre explicar, ou ao aluno crer; cumpre suscitar o espírito de investigação, e o aluno ser atraído a enunciar a verdade em sua própria linguagem".

Assim, é necessário repensar a avaliação para que ela sirva para democratização do ensino, e modificar avaliação passando-a de classificatória para diagnóstica; a avaliação deverá ser assumida como um instrumento de compreensão de estágio de aprendizagem em que se encontra o educando, tendo em vista tomar decisões suficientes e satisfatórias para que possa avançar seu processo de aprendizagem.

A avaliação diagnóstica tem como objetivo determinar a presença ou a ausência de pré-requisitos, assim como identificar as possíveis causas de dificuldades de aprendizagem. Ela além de ser mais democrática respeita as diferenças, as individualidades e as características pessoais de cada aluno. $\mathrm{E}$, quando se trata de educação de adultos parece ser a mais eficiente por oferecer a oportunidade de começar ou recomeçar sabendo quais os caminhos percorrer para que se efetue a aprendizagem. Conforme Freire (1996) "é imprescindível, portanto, que a escola instigue constantemente a curiosidade do educando em vez de amacia-lo ou domesticá-lo".

Quando ao ato de avaliar parte de uma avaliação diagnóstica, que é um dos meios pelos quais se podem conhecer os alunos e saber de que forma é possível modificar, adequar; não somente o planejamento bem como todo o processo de ensino-aprendizagem, pois somente ela é capaz de acompanhar item por item. É ela que vai permitir uma leitura e análise dos meios de verificação de problemas de aprendizagem ou de potencialidades dos educandos

A diferença entre uma avaliação tradicional que na maioria das vezes é excludente e uma avaliação diagnóstica, de processo e formativa é que a primeira delas tem como objetivo uma espécie de 'domesticação' do indivíduo e a segunda pretende a sua humanização. Com função classificatória a avaliação constitui-se em um instrumento estático e que impede o processo de crescimento; já com função diagnóstica ela passa ser um momento dialético do processo de avançar, de crescimento, de autonomia. A avaliação diagnóstica é utilizada para verificar os conhecimentos que os alunos têm, os pré-requisitos que apresentam as suas particularidades e, no que se trata a avaliação de jovens e adultos é necessariamente uma das primeiras avaliações que ocorre para o conhecimento do nível de aprendizagem que o aluno possui e assim se possível saber quais serão os melhores procedimentos metodológicos vão ser melhores para garantir uma melhor aprendizagem.

Rabelo (1998) confirma que a avaliação diagnóstica deve ocorrer no início do processo e tem como objetivos: orientar, explorar, identificar, adaptar, predizer; enquanto o aluno é visto como produtor. A avaliação aqui busca conhecer, principalmente as aptidões, os interesses e capacidades e competências enquanto pré-requisitos para futuros trabalhos. Para ele a avaliação formativa deve ocorrer durante o 
processo e deverá ter como objetivos: regular, situar, compreender, harmonizar, tranquilizar, apoiar, reforçar, corrigir, facilitar, dialogar para que se tenham informações sobre estratégias de solução dos problemas e das dificuldades surgidas.

\section{Avaliação Formativa ${ }^{7}$}

Esse tipo de avaliação conforme sugerida por Rabelo (2001), deve ocorrer durante o processo educativo, ou seja, enquanto são realizadas as atividades com os alunos no processo de produção. Nesse sentido para Perrenoud (2000), "ninguém formará competências na escolaridade básica se não forem exigidas competências no momento da certificação. A avaliação é o que realmente conta". As práticas de avaliação parecem por outro lado, naturais a todos aqueles que, em seu trabalho, estão habituados a fazer um balanço das perdas e dos ganhos após um exercício realizado. Quando se fala do sistema de avaliação, a escola parece ainda muito próxima daquilo que os pais conheceram em sua época, mesmo quando deixaram à escola há alguns anos.

É a avaliação que vai permitir o conhecimento desses fatos e possibilidades. Os pais preocupados com a situação de seus filhos aprendem que o bom uso das informações dadas pela escola sobre todos os acontecimentos relacionados ao processo de ensino-aprendizagem, a prática pedagógica e a avaliação é que vão garantir que esse elo de comunicação seja útil tanto para a escola quanto para a família. Para Jorba et al. (2003), a avaliação tem caráter "pedagógico ou formativo, pois contém informação útil para a adaptação das atividades de ensino aprendizagem às necessidades dos alunos e, desse modo, melhora a qualidade do ensino em geral".

No entanto, o que se percebe muitas vezes é que há um descompasso entre a prática da escola, a realidade do aluno e a comunicação com a família, principalmente quando se trata de avaliação. Assim, há necessidade de mudança no sistema de avaliação. Contudo, está somente é formativa se desemboca em uma forma ou outra de regulação de ação pedagógica ou das aprendizagens, uma modificação do ritmo, do nível global ou do método de ensino para o conjunto da turma. Para Sanmartí (2009), "essa visão da avaliação formativa possibilita que os professores desenhem estratégias não baseadas na repetição e dirigidas a combater as causas da dificuldade". A mudança das práticas de avaliação é então acompanhada por uma transformação do ensino, da gestão da aula, do cuidado com os alunos em dificuldade, entre momentos de apoio interno ou externo e verdadeiras pedagogias diferenciadas.

Por vezes, professores sobrecarregados temem qualquer mudança, os obstáculos provêm da rigidez no horário escolar, no programa, nas regras, nos valores e nas representações dos agentes. Enquanto o professor for obrigado a administrar um grande número de provas a todos os alunos de forma sincrônica e padronizada, restará menos tempo para praticar a avaliação formativa. Segundo ainda Perrenoud, "uma

\footnotetext{
${ }^{7}$ A avaliação formativa, é realizada durante todo o decorrer da alfabetização, com o intuito de verificar se os alunos estão atingindo os objetivos previstos. É também utilizada para que os alunos conheçam seus erros e acertos e encontrem estímulo para um estudo sistemático. Ela permite o feedback no desenvolvimento do processo ensino - aprendizagem além de permitir aos indivíduos a possibilidade de correção de falhas, esclarecimentos de dúvidas e estímulo a continuação do trabalho para alcance do objetivo. Garante ainda informações a respeito do desenvolvimento do trabalho, adequação de métodos e materiais segundo Hoffmann (1996).
} 
avaliação formativa coloca à disposição do professor informações mais preciosas, mais qualitativas sobre os processos de aprendizagem, as atitudes e as aquisições dos alunos" (1999). A avaliação formativa desenvolve uma pedagogia diferenciada pouco preocupada com os conteúdos específicos dos ensinos e das aprendizagens, pois, está baseada em objetivos mais explícitos, coleta de informações mais qualitativas e regulares e intervenções mais diversificadas, saber para quais domínios entende-se conduzir os alunos e em quais caminhos se pretende intervir junto a eles. Ao professor ainda, cabe a possibilidade de diagnosticar também qual é o melhor caminho a trilhar e quais são ou serão os trabalhos mais eficientes para que sejam atingidos os objetivos. Além disso, é possível captar as necessidades dos alunos em termos de aprendizagem também em termos de ensino.

A avaliação diagnóstica necessariamente precisa, a partir de um ponto de partida para o conhecimento do aluno e do seu potencial, demonstrar que o processo de aprender prevê não somente a verificação do erro, dos problemas e dos defeitos, mas que a partir de um determinado ponto de partida continuamente se busque a qualidade. E assim, que acima de tudo se dê e aconteça o conhecimento e a transformação deste. Já a "avaliação formativa deve ser proporcional às necessidades, concentrando seus esforços no aluno com maiores dificuldades" (PERRENOUD, 2000). Dessa forma é necessário que a avaliação seja sistemática durante todo o processo de ensino-aprendizagem. Na medida em que os trabalhos decorrem no processo a avaliação se dá com o objetivo de melhorar, aperfeiçoar e verificar o grau de assimilação de alguns objetivos previamente estabelecidos.

Sanmartí (2003) considera que, "a avaliação formativa responde a uma concepção do ensino que considera que aprender é um longo processo por meio do qual o aluno vai reestruturando seu conhecimento". Ela tem a finalidade de proporcionar informações acerca do desenvolvimento do processo de ensino e aprendizagem, com o fim de que o professor possa ajustá-lo às características das pessoas a que se dirige. Avaliação formativa serve como fornecimento de informações a serem utilizadas na melhoria de um programa em suas partes ou o seu todo e somativa consiste no fornecimento de informações sobre o valor final de um programa institucional. Bloom et al. (1983), afirmam que é, "necessário investigar os tipos de evidências mais úteis ao processo, procurar o melhor método de relatar estas evidências, e encontrar formas de reduzir os efeitos negativos associados à avaliação". Na escola, uma avaliação formativa demanda uma cooperação igualmente grande. Para realizá-la, é preciso romper com as estratégias habituais dos alunos e exige um tipo de revolução cultural, baseada em uma confiança recíproca e uma cultura comum que tornam a transparência possível.

\section{Avaliação Somativa}

Tem por objetivo uma análise mais geral para verificar se os objetivos mais gerais foram alcançados. Aqui os resultados podem ser expressos em notas e conceitos, pois aqui a avaliação tem como objetivo fornecer dados e resultados para a secretaria, boletins de pais e o fechamento de um processo, haja vista ela ocorra no final de uma unidade de ensino. Ou então, de um planejamento previamente elaborado ela vai determinar o grau de domínio e permitirá um balanço somatório fazendo com que seja possível fazer um 
inventário para considerações finais possibilitando uma certificação ou titulação. Deve a avaliação, permitir que o professor possa adquirir os elementos de conhecimento para melhoria no processo ensinoaprendizagem e deve servir não só para a melhoria do produto final, mas sim do processo de formação. Segundo Bloom et al. (1983) o ensino-aprendizagem deve ter a intenção de preparar o estudante. O processo de avaliação deve ter a intenção de verificar se o estudante desenvolveu de maneira esperada.

\section{CONCLUSÕES}

Considera ser que o presente artigo trouxe a proposição para um novo olhar diante da avaliação na educação de jovens e adultos. Esta possibilita uma reflexão, mostrando a importância do assunto e a imensidade de discussões que existem acerca do tema, por meio de autores que escreveram que discutem o assunto. Assim, é possível afirmar quanto à concepção de avaliação, que todo o professor tem a responsabilidade de avaliar o desempenho e o aprendizado do aluno, alcançando seu objetivo proposto. É comum alguns casos em que o professor diz não saber até que ponto a avaliação interfere no processo de ensino-aprendizagem, e que atitudes tomarem.

Para tanto, com este trabalho de pesquisa teórica foi possível entender que não é só a nota que identifica a qualidade de ensino, mas o aprendizado dos educandos e seu desempenho que demonstra o quanto evoluiu em relação aos objetivos propostos. Nesse sentido, conclui se que a avaliação libertadora tem como função ajudar a escola a cumprir o seu papel social de transformadora favorecendo a melhor aprendizagem e visando uma sociedade mais justa e solidária. É preciso que a avaliação sirva necessariamente para a emancipação dos sujeitos e melhor posição deles no meio social em que estão inseridos.

\section{REFERÊNCIAS}

ARAÚJO, C. H.. O segredo é avaliar sempre. Nova Escola, São Paulo, v.22, n.199, p.42-43, 2019.

BERGER, M. A.. Avaliação educacional. Aracaju: UNIT, 2011.

BRASIL. Parâmetros Curriculares Nacionais: Introdução: Educação de Jovens e Adultos. Brasília: MEC, 1999.

BLOOM, B. S.; HASTINGS, J. T.; MADAUS, G. F.. Manual de avaliação formativa e somativa do aprendizado escolar. São Paulo: Livraria Pioneira, 1983.

FREIRE, P.. Educação e mudança. Rio de Janeiro: Paz e Terra, 1983.

FREIRE, P.. Pedagogia da Autonomia a Prática Educativa. São Paulo: Paz e Terra, 1996.

GADOTTI, M. Pedagogia da Terra. São Paulo: Peirópolis, 2001.

GANDIN, L. A.. Educação libertadora: avanços, limites e contradições. Petrópolis: Vozes, 1988.

HADJI, C.. Avaliação desmistificada. Porto Alegre: Artmed,
2001.

HOFFMANN, J. M. L.. Avaliação: mito e desafio: uma perspectiva construtivista. Porto Alegre: Educação e Realidade, 1991.

HOFFMANN, J.. Avaliação Mediadora. Porto Alegre: Mediação, 1993.

HOFFMANN, J.. Avaliação mediadora: uma prática em construção da pré-escola à universidade. Porto Alegre: Educação Realidade, 1995.

HOFFMANN, J. M. L.. Avaliação na Pré-escola: um olhar sensível e reflexivo sobre a criança. 7 ed. Porto Alegre: Mediação, 1996.

HOFFMANN, J. M. L.. Avaliação Mediadora: uma relação dialógica na construção do conhecimento. Porto Alegre: Mediação, 2000.

JORBA, J.; SANMARTÍ, N.. A função pedagógica da avaliação. In: BALLESTER, M.. Avaliação como apoio à aprendizagem. Porto Alegre: Artmed, 2003. p.23-45 
LIBÂNEO, J. C.. Pedagogia e pedagogos: inquietações e buscas. In: ENCONTRO CEARENSE DE EDUCADORES PROMOVIDO PELO OFINARTES, 2. Anais. Fortaleza: Centro de Acessória Pedagógica, 1999.

LUCKESI, C. C.. Avaliação educacional: pressupostos conceituais. Tecnologia Educacional, n.24, p.5-9, 1978.

LUCKESI, C. C.. Avaliação educacional escolar: para além do autoritarismo. Revista de Educação AEC, Brasília, v.15, n.60, p.23-37, 1986.

LUCKESI, C. C.. Avaliação da aprendizagem escolar: estudos, proposições. 3 ed. São Paulo: Cortez, 1996.

PERRENOUD, P.. Dez Novas Competências para Ensinar. Porto Alegre: Artes Médicas, 2000

PERRENOUD, P.. Avaliação: da excelência à regulação das aprendizagens - entre duas lógicas. Porto Alegre: Artes
Médicas Sul, 1999.

RABELO, E. H.. Avaliação: novos tempos, novas práticas Petrópolis: Vozes, 1998.

SAVIANI, D.. Filosofia da educação brasileira: Civilização Brasileira. Rio de Janeiro, 1985.

SANMARTÍ, N.. Avaliar para aprender. Porto Alegre: Artmed, 2003.

SANMARTÍ, N.. Avaliar para aprender. Porto Alegre: Artmed, 2009.

WHITE, E. G.. Conselhos aos Professores, Estudantes. 3 ed. Santo André: Casa Publicadora Brasileira, 1976.

VASCONSELLOS, C. S.. Avaliação: concepção dialéticolibertadora do processo de avaliação escolar. São Paulo: Libertad, 1994.

A CBPC - Companhia Brasileira de Produção Científica (CNPJ: 11.221.422/0001-03) detém os direitos materiais desta publicação. Os direitos referem-se à publicação do trabalho em qualquer parte do mundo, incluindo os direitos às renovações, expansões e disseminações da contribuição, bem como outros direitos subsidiários. Todos os trabalhos publicados eletronicamente poderão posteriormente ser publicados em coletâneas impressas sob coordenação da Sustenere Publishing, da Companhia Brasileira de Produção Científica e seus parceiros autorizados. Os (as) autores (as) preservam os direitos autorais, mas não têm permissão para a publicação da contribuição em outro meio, impresso ou digital, em português ou em tradução. 